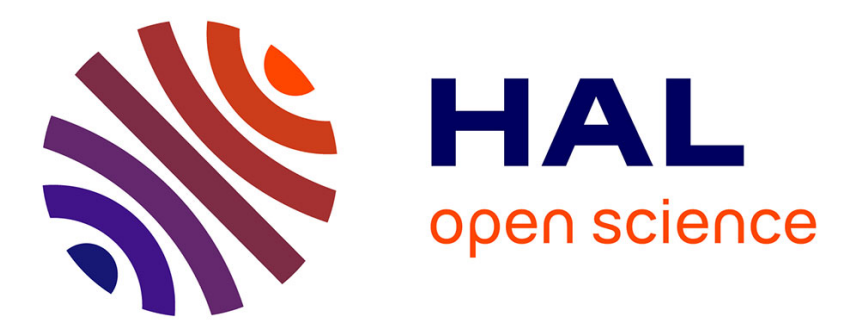

\title{
Hydrogen contribution to the thermal expansion of hydrided Zircaloy-4 cladding tubes
}

Arthur Hellouin de Menibus, Thomas Guilbert, Quentin Auzoux, Caroline Toffolon, Jean Christophe Brachet, Jean Luc Béchade

\section{- To cite this version:}

Arthur Hellouin de Menibus, Thomas Guilbert, Quentin Auzoux, Caroline Toffolon, Jean Christophe Brachet, et al.. Hydrogen contribution to the thermal expansion of hydrided Zircaloy-4 cladding tubes. Journal of Nuclear Materials, 2013, 440, pp.169-177. 10.1016/j.jnucmat.2013.04.039 . hal-00830844

HAL Id: hal-00830844

https://hal-mines-paristech.archives-ouvertes.fr/hal-00830844

Submitted on 8 Oct 2013

HAL is a multi-disciplinary open access archive for the deposit and dissemination of scientific research documents, whether they are published or not. The documents may come from teaching and research institutions in France or abroad, or from public or private research centers.
L'archive ouverte pluridisciplinaire HAL, est destinée au dépôt et à la diffusion de documents scientifiques de niveau recherche, publiés ou non, émanant des établissements d'enseignement et de recherche français ou étrangers, des laboratoires publics ou privés. 


\title{
Hydrogen contribution to the thermal expansion of hydrided Zircaloy-4 cladding tubes
}

Arthur Hellouin de Menibus*1,2, Thomas Guilbert ${ }^{3}$, Quentin Auzoux ${ }^{1}$, Caroline Toffolon ${ }^{3}$, Jean-Christophe Brachet ${ }^{3}$, and Jean-Luc Bechade ${ }^{3}$

${ }^{1}$ CEA Saclay/DEN/DANS/DMN/SEMI/LCMI, 91191 Gif-sur-Yvette, France ${ }^{2}$ Mines ParisTech/Centre des materiaux CNRS UMR 7633, 91003 Evry, France

${ }^{3}$ CEA Saclay/DEN/DANS/DMN/SRMA, 91191 Gif-sur-Yvette, France

Published in 2013 in the Journal of Nuclear Materials, http://www.sciencedirect.com/science/article/pii/S0022311513006478

\begin{abstract}
This study is focused on the hydrogen-induced dimensional change or "growth" of zirconium alloys. Dilatometric experiments were performed on samples taken from a unirradiated Zircaloy-4 (Zy-4) fuel cladding loaded up to $940 \mathrm{wppm}$ hydrogen. Samples were taken in the axial direction of the tube or at $45^{\circ}$ to the axial and transverse directions. The results indicate that hydrogen-induced expansion is anisotropic. Theoretical expansion calculations were carried out considering the partition of hydrogen in solid solution and hydrides together with the material crystallographic texture. Hydride-induced expansion was calculated using two different assumptions reported in the literature, namely "Pure Lattice Transformation Strains" (PLTS) and "Pure Shear Transformation Strains" (PSTS). Calculations based
\end{abstract}

*Tel.: +3316908 39 43; e-mail: arthur.hellouin-de-menibus@cea.fr 
on the PSTS hypothesis satisfactorily predicted the anisotropy observed in the dilatometric curve. Under this assumption, the contribution of hydrides to the axial growth of high-burnup Zy-4 cladding is limited to $12 \%$. This study shows it is important to consider the respective contribution of hydrogen in both states, together with the material crystallographic texture, to understand the dilatometric behavior of hydrided zirconium alloys.

Keywords: zirconium, Cladding Tube, Hydrogen, Hydride, Dimensional stability.

\section{Introduction}

Nuclear fuel cladding fabricated from zirconium based alloys suffer dimensional changes during reactor exposure due to irradiation, diametral and axial creep, ratcheting due to pellet cladding interaction, and corrosion. These dimensional changes are a matter of concern and must be taken into account to avoid any complications during reactor operation or handling of the fuel rods. Quantitative identification of the respective contributions of the causes to the dimensional variations is important in order to understand the differences that may arise between different zirconium alloys used in fuel assemblies. Corrosion effects on cladding dimensional stability could be due to the development of stresses in the growing oxide layer [1] and to progressive hydrogen pick up. The present paper is focused on the hydrogen contribution. Hydrogen could be present in two states: in solid solution or in the form of hydrides that form when hydrogen atoms combine with zirconium atoms when the solubility limit is surpassed at a given temperature. Three different hydride crystallographic structures are generally reported. The precise conditions leading to the formation of the different phases are still not fully understood, but the $\delta$ phase is the most commonly observed after reactor exposure or in the laboratory. The $\varepsilon$ phase generally appears at high hydrogen content. The $\gamma$ phase formation is not completely understood yet. It is often observed after fast cooling [2], while other studies showed it is stable at low temperature [3], and some authors indicate it may be a transition phase from zirconium toward $\delta$-hydrides [4]. One may refer to $[5,6,7]$ for details on the conditions for which the hydride phases appear. The present study is focused on $\delta$ hydrides. While the cladding expands by hydrogen pick up, the expansion magnitude could depend on whether the hydrogen is 
in solid solution or in the precipitated form. Dilatometric experiments on hydrided material with samples taken in two directions have been reported in [8]. It indicated that the hydrogen contribution to material expansion is anisotropic.

The purpose of this work is to investigate the role of hydrogen in Zy4 dimensional changes by calculating separately the solid solution and the hydride contributions along with the material texture. These analyses are validated by dilatometric measurements carried out on specimens hydrided up to 940 wppm, with samples taken in two different directions. These experiments were performed at the CEA/SRMA between 1999 and 2001 and were only partially published in [8].

\section{Procedures}

\section{$2.1 \quad$ Experimental}

\subsubsection{Material}

The material consists in CWSR Zircaloy-4 tubes, which is commonly used for fuel claddings in PWRs. Its weight composition is 1.2 to $1.7 \% \mathrm{Sn}, 0.18$ to $0.24 \% \mathrm{Fe}, 0.07$ to $0.13 \% \mathrm{Cr}, 0.1$ to $0.14 \% \mathrm{O}$, Zr balance, according to the ASTM B 350.90 specification. In order to test different textures, some samples named " 0 " were cut in the axial direction, and others samples named " $45^{\circ} "$ were cut at $45^{\circ}$ to the axial direction of flattened tubes (Figure 1). Therefore, $0^{\circ}$ samples have a curvature similar to that of the initial tube, but $45^{\circ}$ are planar. Samples measured $12 \times 3.3 \times 0.57 \mathrm{~mm}$.

The texture of the material was measured by X-Ray diffraction. Kearns factors along the $12 \mathrm{~mm}$ direction are 0.09 and 0.25 for the $0^{\circ}$ and $45^{\circ}$ samples respectively. These factors are representative of axial and circumferential directions for Zy-4 guide tubes or cladding, where the zirconium $\langle c\rangle$ axes are included in the radial-circumferential plane at $\pm 30^{\circ}$ of the radial direction (Murty et al. [9]). Considering typical recrystallized grain size of about $5 \mu m$, the smallest sample dimension, which is the thickness, contains more than 100 grains. The measured texture can therefore be used as a meaningful statistical value for the different tested samples. 


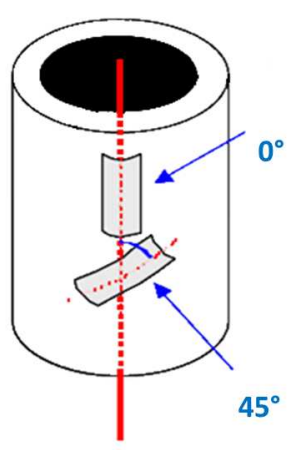

(a)

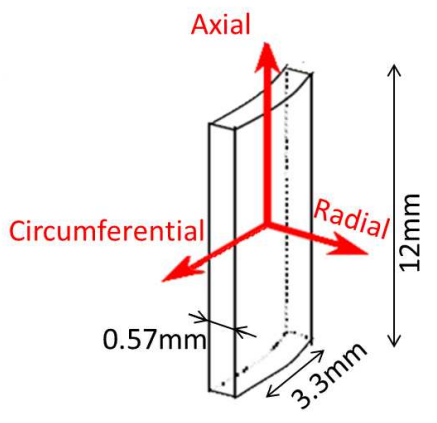

(b)

Figure 1: Schematic description of the (a) $0^{\circ}$ and $45^{\circ}$ samples used and (b) Sample geometry.

\subsubsection{Hydriding}

The as received material hydrogen content is $10 \mathrm{wppm}$. Additional hydriding was performed by gaseous charging at $400{ }^{\circ} \mathrm{C}$ to reach hydrogen contents up to $940 \mathrm{wppm}$. The cooling rate was about $2{ }^{\circ} \mathrm{C} / \mathrm{min}$, which is slow enough to promote $\delta$-hydrides precipitation. Observations with an optical microscope showed the hydrogen was homogeneously distributed in the cladding, without any over-concentration close to specimen surface. Hydrogen concentration was measured by destructive fusion analysis at both extremities of each sample with $10 \%$ accuracy. The hydrogen variation between the two coupons of a sample was about $13 \%$ on average.

\subsubsection{Dilatometric measurements}

Dilatometric measurements were performed on an ADAMEL LHOMARGY DT-1000 dilatometer monitoring the specimen length with a $0.2 \mu \mathrm{m}$ theoretical resolution in dimensional measurement. The $0^{\circ}$ and $45^{\circ}$ samples were heated from $20^{\circ} \mathrm{C}$ to $650^{\circ} \mathrm{C}$ at a rate of $10^{\circ} \mathrm{C} / \mathrm{min}$ and $45^{\circ} \mathrm{C} / \mathrm{min}$ respectively. These two heating rates for the $0^{\circ}$ and $45^{\circ}$ samples do not affect our conclusions as explained later on. Dilatometric tests were carried out on unhydrided and hydrided samples. The dilatometric experiments were performed three times per sample, which showed that the results are highly reproducible. 


\subsection{Calculation procedures}

\subsubsection{Hydrogen solubility limit}

The solubility limit of hydrogen in zirconium determines the hydrogen fraction in solid solution and in the form of precipitates at a given temperature. Only the solubility limit in dissolution, usually named "TSSD" for Terminal Solid Solubility in Dissolution, is used in this study, which is restricted to the heating phase. The solubility limit TSSD identified by various authors shows a large scatter (Figure 2). The TSSD identified in Kammenzind et al. [10] on unirradiated Zy-4 material was arbitrarily chosen for the present study calculations. However, calculations were also performed using the TSSD equation determined by Kearns et al. [11] and Tang et al. [12], and these other models led to the same conclusions.

\subsubsection{Expansion due to hydrogen in solid solution}

The molar partial volume of hydrogen corresponds to the expansion of the zirconium lattice induced by the insertion of $1 \mathrm{~mol}$ of hydrogen atoms. For pure zirconium, the partial volume of deuterium is $1.67 \mathrm{~cm}^{3} / \mathrm{mol}$ in the range $450-500{ }^{\circ} \mathrm{C}$ (Mac Ewen et al. [19]), in close agreement with the $1.7 \mathrm{~cm}^{3} / \mathrm{mol}$ reported in Eadie et al. [20] at $300{ }^{\circ} \mathrm{C}$ for hydrogen. The lack of additional experimental data leads us to assume that the contribution of hydrogen in solid solution to zirconium expansion is independant of temperature. The neutron diffraction experiment of Mac Ewen et al. [19] indicates that this expansion is anisotropic, it is about $\varepsilon_{s s, a}=3.29 \%$ and $\varepsilon_{s s, c}=5.42 \%$ for a hydrogen concentration equivalent to $Z r H_{x=1}$ and with ss is the acronym for solid solution. The expansion is therefore 1.65 times higher in the $\langle c\rangle$ direction than in the $\langle a\rangle$ direction of the zirconium crystal. It is close to the 1.47 value reported in Zanellato et al. [21] obtained by in-situ XRay diffraction. The volumetric expansion can be calculated from these two directional expansion coefficients (Equation 1) :

$$
\varepsilon_{s s, \text { volume }}=\varepsilon_{s s, c}+2 \varepsilon_{s s, a}+2 \varepsilon_{s s, a} \varepsilon_{s s, c}+\varepsilon_{s s, a}^{2}+\varepsilon_{s s, c} \varepsilon_{s s, a}^{2}=12.46 \%
$$

This volume increase in $\%$ for a hydrogen concentration equivalent to $Z r H_{x=1}$ is converted in wppm taking into account $Z r H_{x=1}$ is approximately equal to $11000 \mathrm{wppm}$, so $\varepsilon_{\text {ss,volume }}=12.46 \% / Z r H_{x=1}$ corresponds to $\varepsilon_{\text {ss,volume }}=$ $0.00113 \% / w p p m$. The molar partial volume of hydrogen can be obtained 


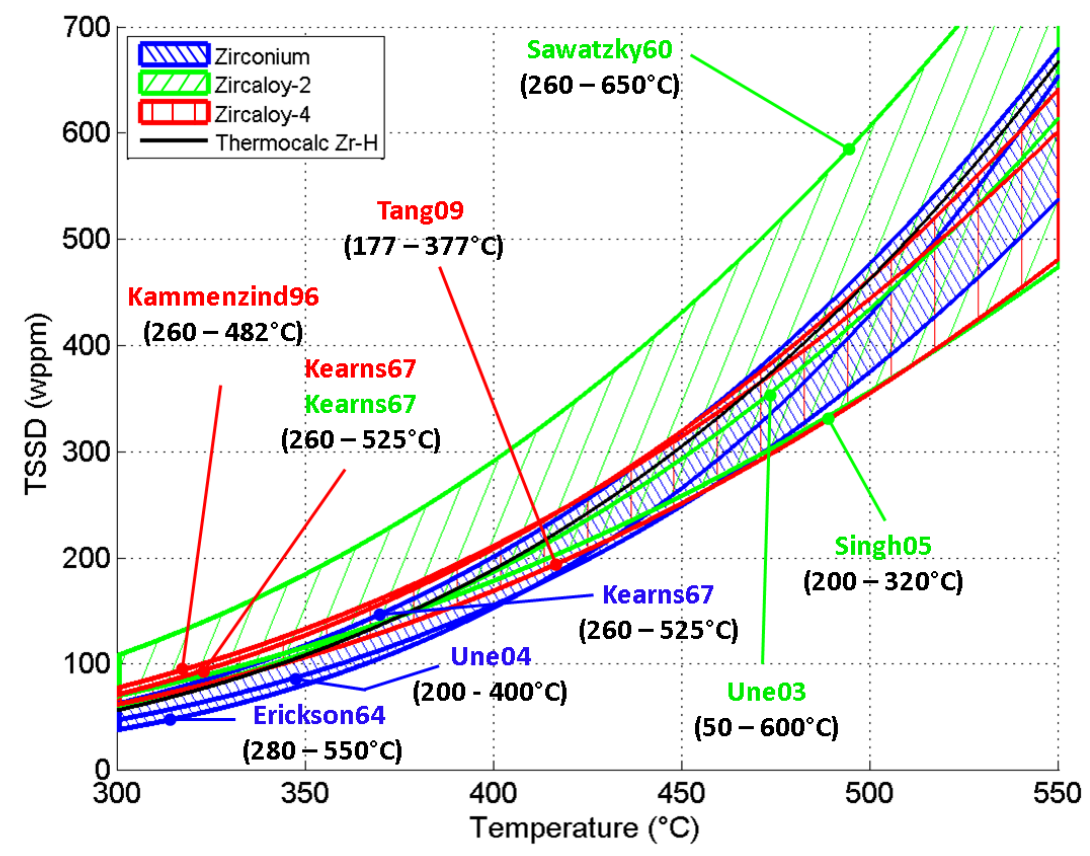

Figure 2: Solubility limit in dissolution TSSD from various studies ([10, 11, $12,13,14,15,16,17]$ and comparison with the solubility limit thermodynamically computed with Thermo-Calc software for the Zr-H system (calculation procedure described in Dupin et al. [18]). 
again by multiplying by the zirconium volume per atom, which is equal to $2.325 \times 10^{-23} \mathrm{~cm}^{3} /$ at or $14.001 \mathrm{~cm}^{3} / \mathrm{mol}$. The calculations performed in the present study used the $\varepsilon_{s s, a}=3.29 \%$ and $\varepsilon_{s s, c}=5.42 \%$ for a $Z r H_{x=1}$ hydrogen concentration for the hydrogen in solid solution contribution (from Mac Ewen et al. [19]).

\subsubsection{Expansion due to hydrides}

\section{Pure lattice transformation strains (PLTS)}

The free misfit stress "Pure lattice transformation strains" (PLTS) was first calculated for hydride in zirconium in Carpenter [22] who found that $\delta$ hydrides occupy $17.2 \%$ more volume than pure zirconium. The calculation was detailed and extended to higher temperature by Singh et al. [23]. This approach is based on cell volume calculations taking into account the fact that the common relationship between the $\delta$ hydrides microscopic platelets and the zirconium hexagonal structure is equal to $(111)_{\delta} / /(0002)_{\alpha}$. It consists of evaluating the change in volume per zirconium atom when the zirconium hexagonal close-packed (HCP) lattice is transformed into a face-centered cubic (FCC) lattice $\delta$ hydride by considering that the atoms are ellipsoids in contact (because these lattices are close-packed). The expansion is calculated by comparing the pure zirconium lattice parameter (without hydrogen in solid solution) and the zirconium $\delta$ hydride lattice parameter. Therefore, this approach encompasses not only the volume change due to the crystallographic structure change from HCP to FCC, but also the insertion of hydrogen in the metal. The hydrogen-induced expansion considering a $\mathrm{ZrH}_{1.66}$ steochiometry and assuming the hydrogen is only in solid solution is equal to $\varepsilon_{s s, \text { volume }}=12.46 \% \times 1.66=20.7 \%$, while Carpenter [22] found $\varepsilon_{\text {hydride,volume }}=17.2 \%$ for $\delta$-hydrides of similar stoichiometry. This theoretical calculation (the zirconium matrix can clearly not maintain this amount of hydrogen in solid solution) shows the hydrogen precipitation into hydrides leads to an optimization of the hydrogen-occupied volume. Additionally, this indicates that the occupied volume for a given quantity of hydrogen is higher when inserted in solid solution than when incorporated in precipitated hydrides, as will be shown by the dilatometric experiments described later in this paper.

Nevertheless, Carpenter [22] and Singh et al. [23] and several papers in the last 40 years used a $Z r H_{1.66}$ stoichiometry for the limit $\alpha+\delta \rightarrow \delta$ in the 
phase diagram at $25^{\circ} \mathrm{C}$ while it is estimated to be $Z r H_{1.556}$ by Thermo-Calc software calculations performed for pure zirconium (the calculation procedure is detailed in Dupin et al. [18]). The results are reported in Annex A. The $\alpha+\delta \rightarrow \delta$ stoechiometry boundary was fitted with a polynomial expression:

$$
\left\{\begin{aligned}
T S S_{\alpha+\delta \rightarrow \delta}(w p p m)= & -5.039 \times 10^{-6} T^{3}+3.690 \times 10^{-3} T^{2} \\
& -3.135 T+1.785 \times 10^{4}
\end{aligned}\right.
$$

where $\mathrm{T}$ is the absolute temperature in Kelvin. Modification of $\delta$ hydride stoichiometry will affect the $\delta$ lattice parameter. The calculation of volume expansion due to hydride precipitation was done with this $\delta$ phase lower boundary. As recommended in Versaci et al. [24], the lattice parameters for the hexagonal close-packed zirconium provided in Goldak et al. [25] were used:

$$
\left\{\begin{aligned}
a(n m) & =0.322849+1.457 \times 10^{-6} T \\
& +3.37 \times 10^{-10} T^{2}-1.64 \times 10^{-13} T^{3} \\
c(n m) & =0.513956+2.562 \times 10^{-6} T \\
& +1.936 \times 10^{-9} T^{2}+2.45 \times 10^{-13} T^{3}
\end{aligned}\right.
$$

Information about the crystallographic texture is required to convert the monocrystalline volume variation to the polycrystalline one. The thermal expansion in the radial, circumferential and axial directions $\left(\varepsilon_{\text {hydride }, r}, \varepsilon_{\text {hydride }, \theta} d, \varepsilon_{\text {hydride, }, z}\right)$ were expressed using the Kearns parameters $\left(f_{r}, f_{\theta}, f_{z}\right)$ and the expansion in the HCP lattice directions $\left(\varepsilon_{\text {hydride,c }}, \varepsilon_{\text {hydride }, a}\right)$ :

$$
\left\{\begin{array}{l}
\varepsilon_{\text {hydride }, r}=f_{r} \times \varepsilon_{\text {hydride }, c}+\left(1-f_{r}\right) \times \varepsilon_{\text {hydride }, a} \\
\varepsilon_{\text {hydride }, \theta}=f_{\theta} \times \varepsilon_{\text {hydride }, c}+\left(1-f_{\theta}\right) \times \varepsilon_{\text {hydride }, a} \\
\varepsilon_{\text {hydride }, z}=f_{z} \times \varepsilon_{\text {hydride }, c}+\left(1-f_{z}\right) \times \varepsilon_{\text {hydride }, a}
\end{array}\right.
$$

Figure 3 shows that the lattice parameters defined in Equation 3 for zirconium give a consistent expansion coefficient value.

The lattice parameter provided in Yamanaka et al. [27] was used for the FCC lattice of $\delta$ hydrides (Equation 5 where $x$ is the atomic ratio in $\operatorname{ZrHx}$ ):

$$
\left\{\begin{aligned}
a_{\delta-Z r H x}= & 0.4706+4.382 \times 10^{-3} x+(T-298) \times \\
& \left(2.475 \times 10^{-6}+6.282 \times 10^{-6} x+5.8281 \times 10^{-8} x^{2}\right)
\end{aligned}\right.
$$




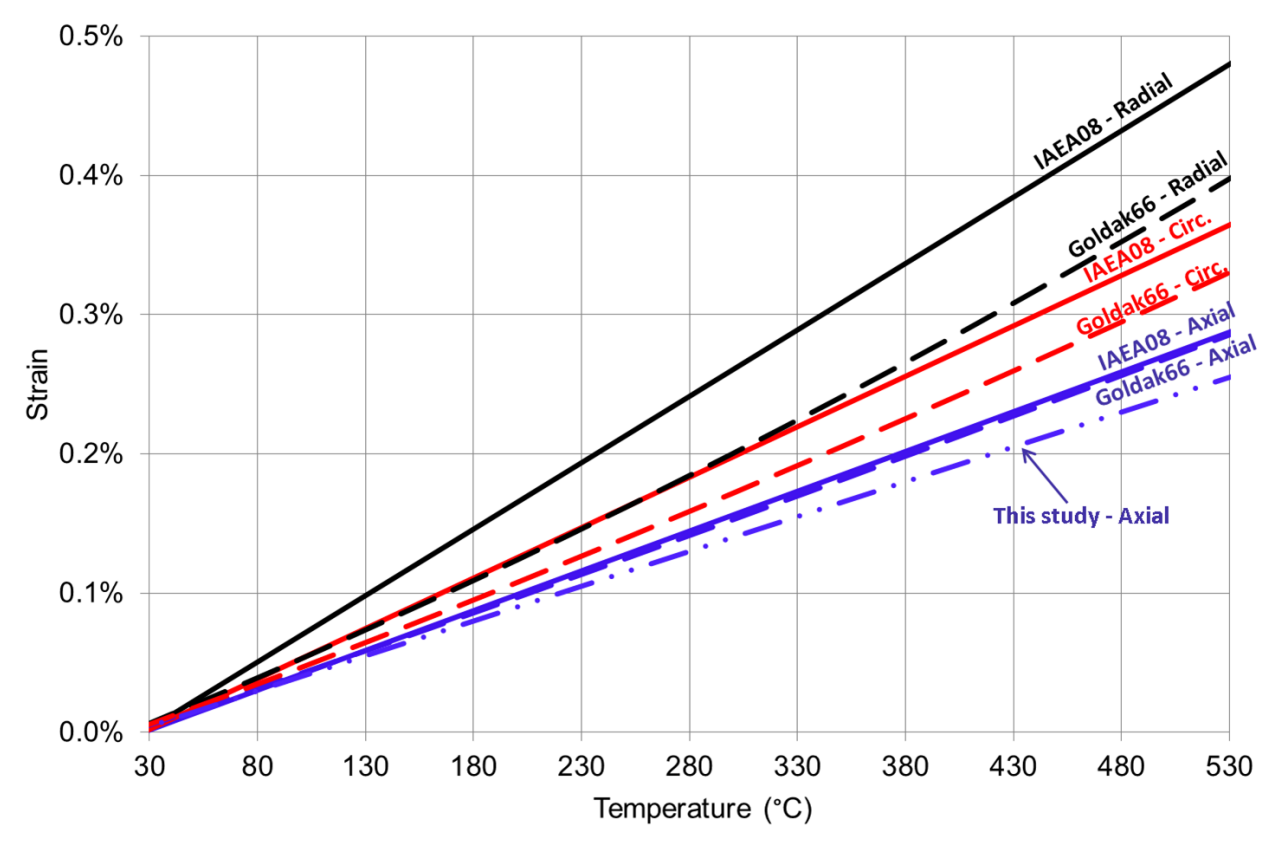

Figure 3: Zirconium thermal expansion computed with the lattice parameters reported in Goldak et al. [25] compared with lattice parameters reported in the IAEA database [26] in axial, circumferential and radial directions, considering a specific texture representative of cladding tubes defined by Kearns parameters $f_{r}=0.6, f_{\theta}=0.3$ and $f_{z}=0.1$. The experimental dilatometric behavior in axial direction from the present study is also displayed. 


\section{Pure shear transformation strains (PSTS)}

This approach is based on the assumption that hydride shape change is equivalent to a martensitic transformation. It has been first proposed in Weatherly [28] for $\gamma$ hydrides and then applied to $\delta$ hydrides in Perovic et al. [29]. In this approach, the total expansion calculated by the PLTS method is assumed to occur exclusively in the direction normal to the habit plane, which is the zirconium $\langle c\rangle$ direction for $\delta$ hydrides. Therefore, following this assumption, hydride precipitation does not induce expansion in the zirconium $<a>$ direction.

\section{Results}

\subsection{Dilatometric experiment}

Experimental dilatometric curves obtained in this study are shown in Figure 4. Comparing the results obtained for unhydrided to hydrided samples for $0^{\circ}$ angle in Figure 4(a) indicates that greater hydrogen contributions lead to increased material dilatation during heating. This increase results from a balance between hydride dissolution, insertion of hydrogen in solid solution, and the presence of undissolved hydrides, which have a higher thermal expansion than the zirconium matrix. The temperature corresponding to the change in slope of the curve, for instance about $430{ }^{\circ} \mathrm{C}$ for the $269 \mathrm{wppm}$ sample, is in close agreement with the hydrogen solubility limit expression provided in Kammenzind et al. [10]. On the other hand, the $45^{\circ}$ angle dilatometric curves displayed in Figure 4(b) show a very limited influence of hydrogen. 


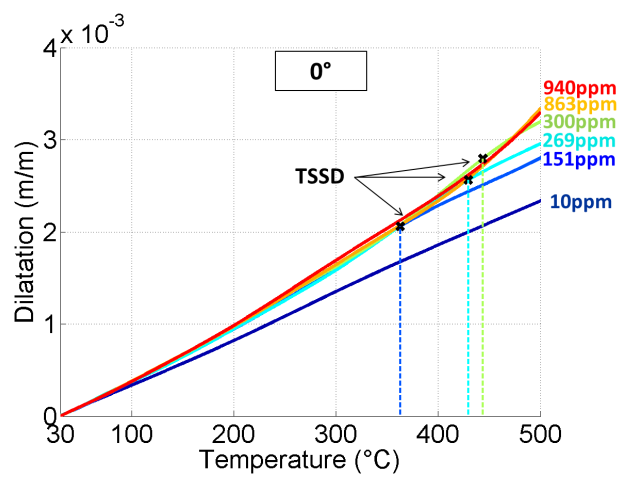

(a)

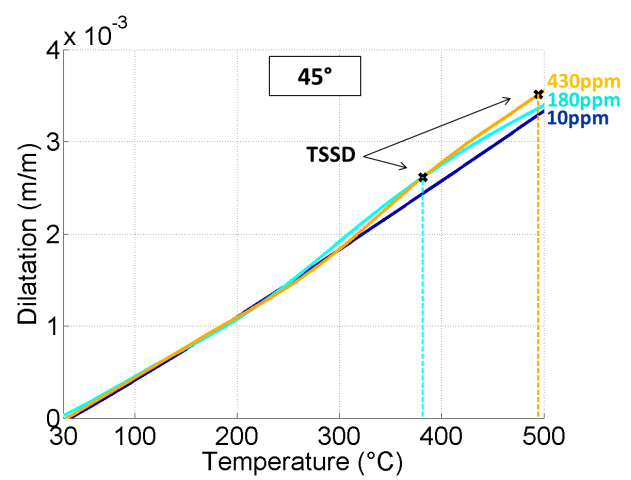

(b)

Figure 4: Results of dilatometric measurements from Zy-4 samples depending on hydrogen concentration in (a) $0^{\circ}$ direction and (b) $45^{\circ}$ direction. 


\subsection{Correction of the hydride precipitation induced expansion with PLTS assumption}

The result of the correction of the $\alpha \rightarrow \alpha+\delta$ domain limit on the hydride expansion calculation is shown in terms of volumetric expansion in Figure 5(a) and directional expansion in Figure 5(b). The trend is no longer linear as the $\alpha \rightarrow \alpha+\delta$ domain limit does not vary linearly with temperature. The numerical value and intermediate calculation results are reported in table 1 . The estimated hydride precipitation-induced expansion at different temperatures in the present study is slightly different from that calculated by Singh et al. [23] with a $Z r H_{1.66}$ stoechiometry. It is nevertheless still valid to keep in mind an approximate $17 \%$ volume expansion at $25^{\circ} \mathrm{C}$. The ratio between expansion along the $\langle c\rangle$ and $\langle a\rangle$ directions $\left(\varepsilon_{\text {hydride, },} / \varepsilon_{\text {hydride, } a}\right)$ decreases from 1.60 to 1.47 from $25^{\circ} \mathrm{C}$ to $500^{\circ} \mathrm{C}$. These values are not much different from the 1.65 anisotropy ratio of the hydrogen in solid solutioninduced expansion $\left(\varepsilon_{s s, c} / \varepsilon_{s s, a}\right)$.

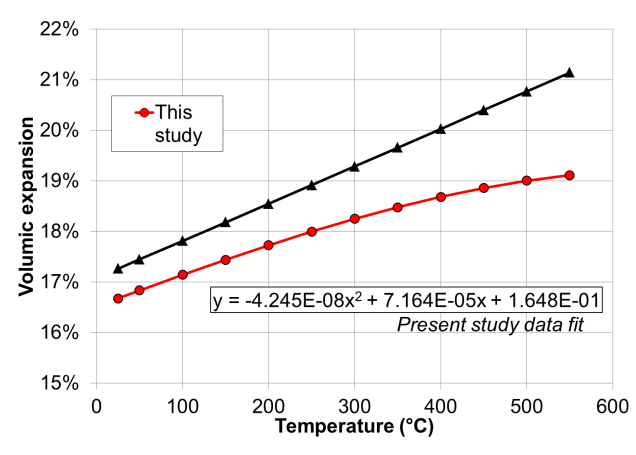

(a)

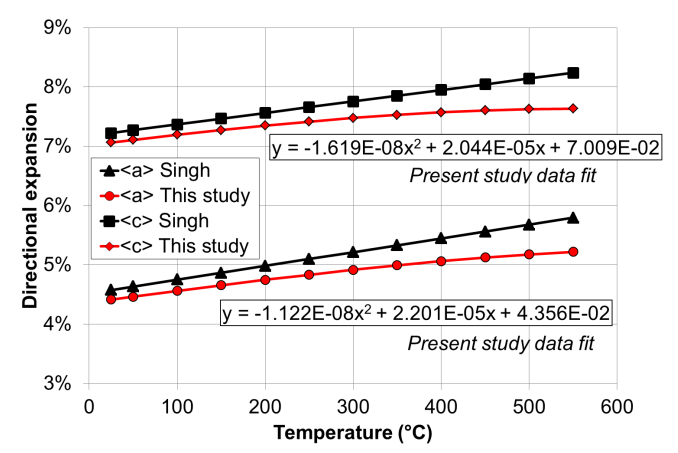

(b)

Figure 5: Calculated (a) volumetric expansion and (b) directional expansion induced by $\delta$ hydrides precipitation following PLTS assumption and comparison with Singh et al. [23]. The indicated equations with $y$ the directional expansion and $x$ the temperature in Celsius degrees were obtained using a least-squares fitting method. 


\begin{tabular}{|c|c|c|c|c|}
\hline & \multicolumn{3}{|c|}{ Temperature $\left({ }^{\circ} \mathrm{C}\right)$} \\
\hline & & 25 & 300 & 500 \\
\hline \multirow{4}{*}{ Zirconium - $\alpha$} & $\mathrm{a}(\mathrm{nm})$ & 0.32331 & 0.32376 & 0.32410 \\
\hline & $\mathrm{c}(\mathrm{nm})$ & 0.51490 & 0.51611 & 0.51721 \\
\hline & Volume lattice $\left(\mathrm{nm}^{3}\right)$ & 0.13990 & 0.14062 & 0.14121 \\
\hline & Volume / at. $\operatorname{Zr}\left(\mathrm{nm}^{3} / \mathrm{at}\right)$ & 0.02332 & 0.02344 & 0.02354 \\
\hline \multirow{4}{*}{ Hydride $-\delta$} & Stoechiometry $\mathrm{x}$ & 1.555 & 1.483 & 1.391 \\
\hline & $\mathrm{a}(\mathrm{nm})$ & 0.47740 & 0.48038 & 0.48208 \\
\hline & Volume lattice $\left(n m^{3}\right)$ & 0.10882 & 0.11085 & 0.11203 \\
\hline & Volume / at. $\mathrm{Zr}\left(\mathrm{nm}^{3} / \mathrm{at}\right)$ & 0.02720 & 0.02771 & 0.02801 \\
\hline \multirow{4}{*}{ Relative Expansion } & Volumetric $\alpha \rightarrow \delta(\%)$ & $16.68 \%$ & $18.25 \%$ & $19.01 \%$ \\
\hline & Direction $\langle a>(\%)$ & $4.58 \%$ & $4.92 \%$ & $5.18 \%$ \\
\hline & Direction $\langle c>(\%)$ & $7.22 \%$ & $7.48 \%$ & $7.63 \%$ \\
\hline & $<c>/<a>(\% / \%)$ & 1.60 & 1.52 & 1.47 \\
\hline
\end{tabular}

Table 1: Hydride induced expansion function of temperature following PLTS assumption 


\subsection{Growth induced by hydrogen pick up at $25^{\circ} \mathrm{C}$}

The expansion of a cladding due to hydrogen uptake is calculated at $25^{\circ} \mathrm{C}$ based on the expansion induced by hydride precipitation and the crystallographic texture. Therefore, the contribution of the hydride's greater thermal expansion and of hydrogen in solid solution is not taken into account. Figures 6 (a) and (b) shows the expansion based on the PLTS (Carpenter [22]) or PSTS (Perovic et al. [29] assumptions respectively. Interestingly, the PLTS assumption results in similar expansion in the circumferential and axial directions, while the PSTS results in a marked anisotropy.

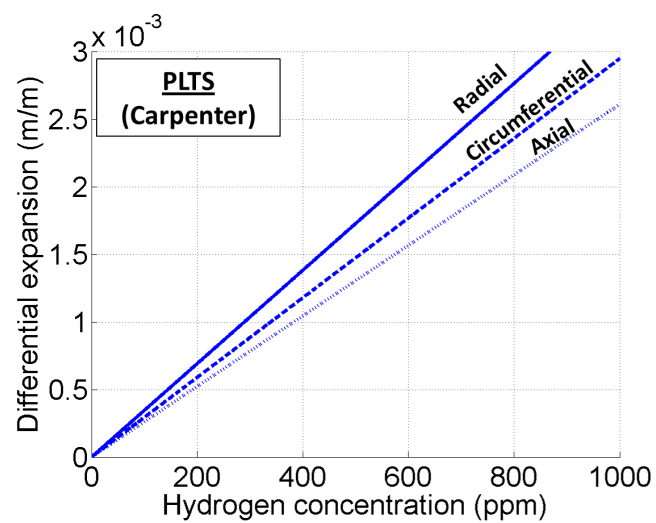

(a)

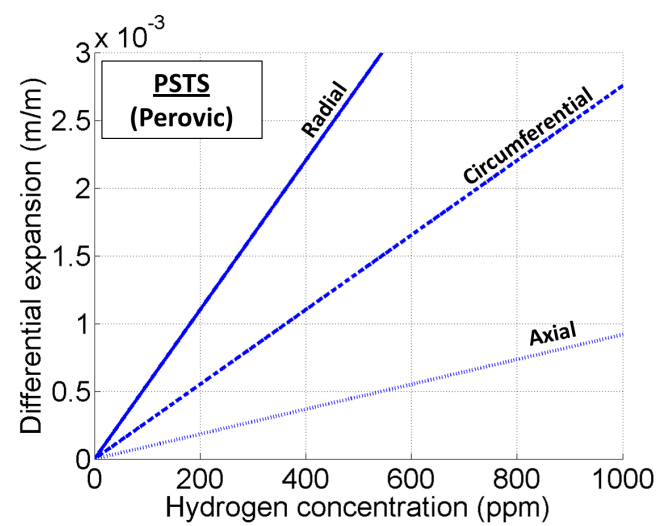

(b)

Figure 6: Expansion induced by hydrogen uptake estimated at $25^{\circ} \mathrm{C}$ with Kearns factors $f_{r}=0.6, f_{\theta}=0.3$ and $f_{z}=0.1$ in case of (a) PLTS and (b) PSTS assumptions. 


\subsection{Total hydrogen contribution to cladding expansion}

The calculated hydrogen contribution to dilatometric behavior of a $500 \mathrm{wppm}$ sample is plotted in Figures 7(a) for PLTS and (b) for PSTS assumptions. This figure represents the calculated difference in thermal expansion between a 500 wppm hydrided sample and an unhydrided sample, which we will refer to as the differential dilatometric curve. The differential dilatometric curve of an unhydrided cladding would be aligned with 0 at all temperatures on such a figure. The red lines correspond to the hydrides, and the green lines correspond to the solid solution contribution. They are added together to obtain the blue line, which represents the total hydrogen contribution. Figures 7(c) and (d) corresponds to a 2000 wppm sample. This high hydrogen content underscores the contribution of undissolved hydrides due to their greater thermal expansion. The total hydrogen contribution computed with the PLTS assumption is linear but results in fact from a combination of hydrides and hydrogen that are both nonlinear. The PSTS assumption leads consistently to a differential dilatometric curve where the radial expansion due to hydride thermal expansion is higher than the circumferential and axial expansions.

A simple calculation can be performed to verify that the contribution of hydrogen in solid solution is consistent. Approximately $400 \mathrm{wppm}$ are in solid solution at $500{ }^{\circ} \mathrm{C}$. The associated expansion is roughly equal to $0.2 \%$ in the radial and $0.15 \%$ in the circumferential and axial directions (green lines in Figure 7). The volumetric expansion is therefore approximately $0.2+0.15+$ $0.15=0.5 \% / 400 \mathrm{wppm}=0.00125 \% / \mathrm{wppm}$, which is close to the $\varepsilon_{\text {ss }, \text { volume }}=$ $0.00113 \% / \mathrm{wppm}$ value determined in section 2.2.2.

The experimental and calculated differential dilatometric curves of the total hydrogen-induced expansion are compared in Figure 8. The PLTS assumption used to obtain Figure 8(a) does not reproduce the observed dilatometric results. Moreover, the PLTS predicts a significant effect of hydrogen content between $200^{\circ} \mathrm{C}$ to $400^{\circ} \mathrm{C}$, which corresponds to thermal expansion of undissolved hydrides, in disagreement with experimental results. On the other hand, the PSTS assumption, used to obtain Figure 8(b), gives values that are in a better agreement with the observed ones. Thus, on estimating hydrogen-induced expansion of cladding, it is important to consider the hydride shape in addition to the atomic volume variation due to hydrogen content of cladding.

At low temperatures $\left(<200^{\circ} \mathrm{C}\right)$, the experimental dilatometric curves rise 
in a linear fashion, while the model estimates a very limited expansion. It is probably not due to a potential underestimation of hydride thermal expansion, as similar behavior is experimentally observed regardless of the hydrogen content. On the other hand, it could be due to a change in the solubility limit behavior at low temperature. This phenomena has been observed in precipitation in Pan et al; [30], Mc Minn et al. [31], Une et al. [15] and Zanellato et al. [21]. Zanellato et al. [21] results show that this phenomenon also occurs to a lesser extent for dissolution at $5{ }^{\circ} \mathrm{C} / \mathrm{min}$ : The change in the slope of the solubility curve takes place around $30 \mathrm{wppm}$, which correspond to $250{ }^{\circ} \mathrm{C}$ to $300^{\circ} \mathrm{C}$. The reason for this phenomenon is still unclear, but Zanellato et al. [21] claim that it could be due to a kinetic effect as they did not observe this effect for a heating rate of $2.5^{\circ} \mathrm{C} / \mathrm{min}$.

The experience-calculation expansion discrepancy at low temperature might also be due to a contribution of the $\gamma$ hydride phase because $\gamma$ quenched hydrides dissolve into solution at significantly lower temperatures than the slower cooled equilibrium hydrides (Tulk et al. [32]). On the other hand, $\gamma$ hydrides potential contribution is not due to a difference in the net volume expansion during hydrides dissolution. Indeed, Carpenter [22] showed the net volume expansion for $\mathrm{ZrH}_{1} \gamma$ hydride precipitation is

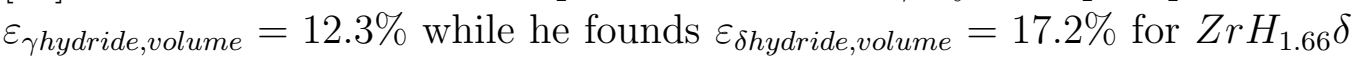
hydrides (it corresponds to $17.2 \% / 1.66=10.4$ for an equivalent $Z r H_{1}$ composition). Thus, the net expansion induced by $\gamma$ hydride dissolution would be slightly lower than the one for $\delta$ hydrides.

At higher temperatures, the calculated curve in Figure 8(b) shows a discontinuity corresponding to the end of hydride dissolution. The observed scatter is likely due to a combination of the uncertainty in the hydrogen content in the samples and in the solubility limit. It is surprising that the experimental dilatometric curve slightly rises at high temperature after all of the hydrides have been dissolved. This could indicate that expansion induced by hydrogen in solid solution depends on temperature, in disagreement with the assumption made for the calculations. Nevertheless, this supports the results of Mac Ewen et al. [19] that directional expansion due to hydrogen in solid solution increases by 5 to $8 \%$ when the temperature is increased from 727 to $777^{\circ} \mathrm{K}$. Mac Ewen et al. [19] did not conclude on a potential temperature dependence as the increase that they observed is nearly equal to the experimental uncertainty, and their measurements were performed at only two temperatures.

As a first conclusion, the comparison of estimated and experimental di- 
altometric curves for the $0^{\circ}$ samples are sufficient evidence that the PSTS model is more accurate. Consequently, the fact that $45^{\circ}$ samples were performed at different heating rates has no impact on our conclusions.

Figure 9 shows the differential expansion of hydrided samples compared to unhydrided samples at $500{ }^{\circ} \mathrm{C}$ as a function of the hydrogen content, using both the PLTS and the PSTS assumptions. This corresponds to the difference between the thermal expansion at $500{ }^{\circ} \mathrm{C}$ of an unhydrided and a hydrided sample. At this temperature, the solubility limit in dissolution is 442 wppm (Kammenzind et al. [10]). Below the solubility limit, the total hydrogen contribution (hydrides plus hydrogen) corresponds to the dissolution of hydrides and the increase of hydrogen in solid solution. Above the solubility limit, the total hydrogen contribution additionnally includes the differential thermal-expansion of the remaining hydrides embedded in the zirconium matrix. Once again, the PLTS assumption does not predict any marked anisotropy in cladding expansion. On the other hand, the PSTS assumption accurately represents the $0^{\circ}$ and $45^{\circ}$ experimental results. The noise in the experimental results might come from the uncertainty in the hydrogen content. Interestingly, the diametral dimension does not present a sharp expansion discontinuity at temperature where the solubility limit is reached. The sharpest volume expansion discontinuity is in the material radial direction (cladding tube thickness), which is therefore the best direction to monitor to detect the solubility limit with dilatometric experiments. Nevertheless, the cladding tube thickness variation is generally difficult to measure accurately due to its small dimensions. Therefore, it appears that the best compromise to measure the solubility limit using dilatometric measurements is by examining the cladding dimensional evolution in the axial direction.

\section{Discussion}

\subsection{Choice of the model of hydride induced expansion for application to claddings}

King et al. [33] performed an extensive study on Zirlo and Zy-4 growth using unirradiated samples, samples that were hydrided in lithine solution, and irradiated guide tubes and strips. The material was in the fully recrystallized state. The authors measured the dimensional changes in the axial and 


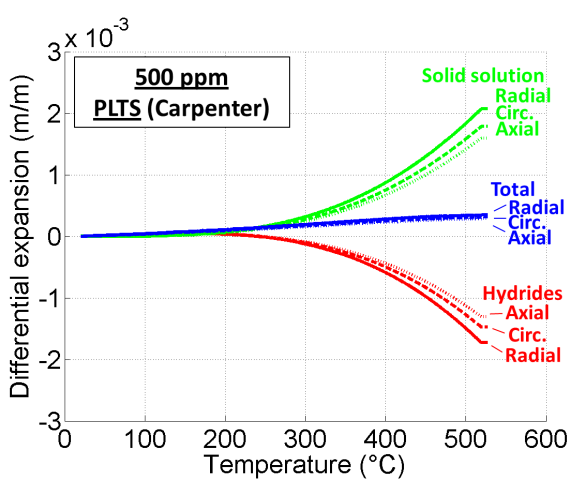

(a)

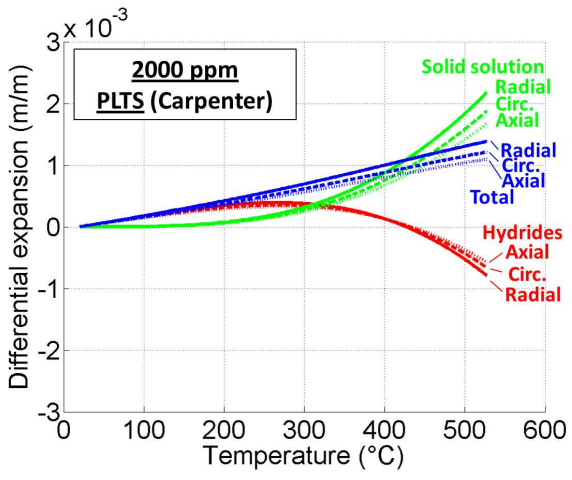

(c)

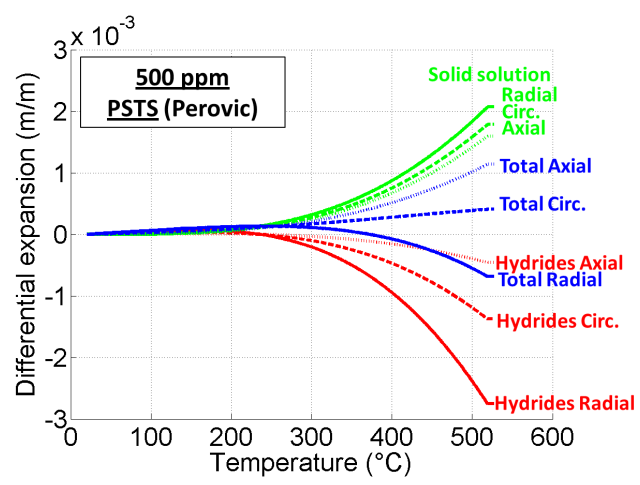

(b)

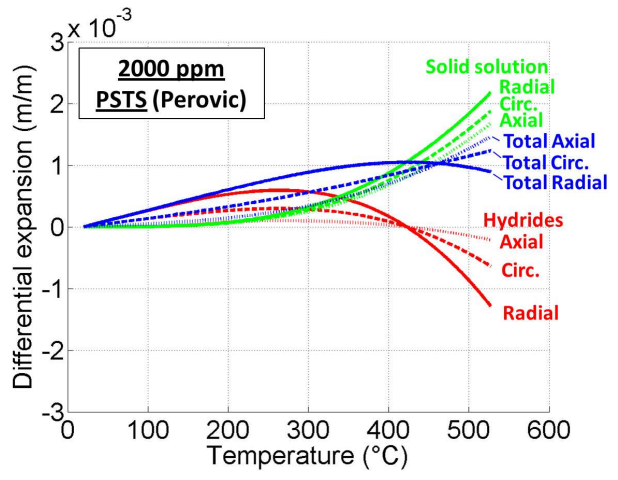

(d)

Figure 7: Differential dilatometric curves estimated for a (a,b) $500 \mathrm{wppm}$ and a (c,d) 2000wpppm sample with $(\mathrm{a}, \mathrm{c})$ coresponding to PLTS and $(\mathrm{b}, \mathrm{d})$ to PSTS assumptions. The Kearns factors are $f_{r}=0.6, f_{\theta}=0.3$ and $f_{z}=0.1$. 


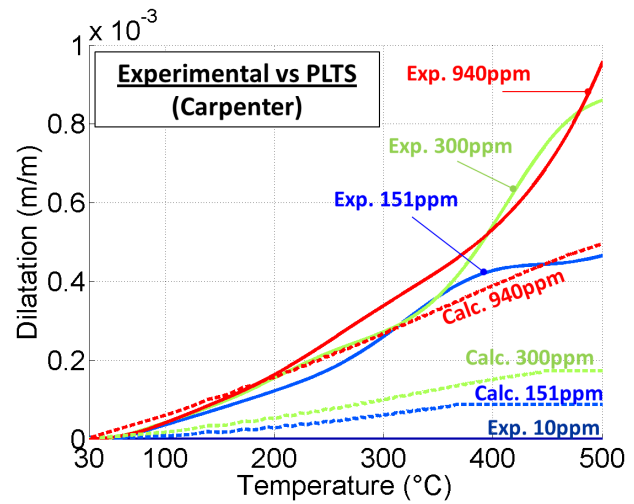

(a)

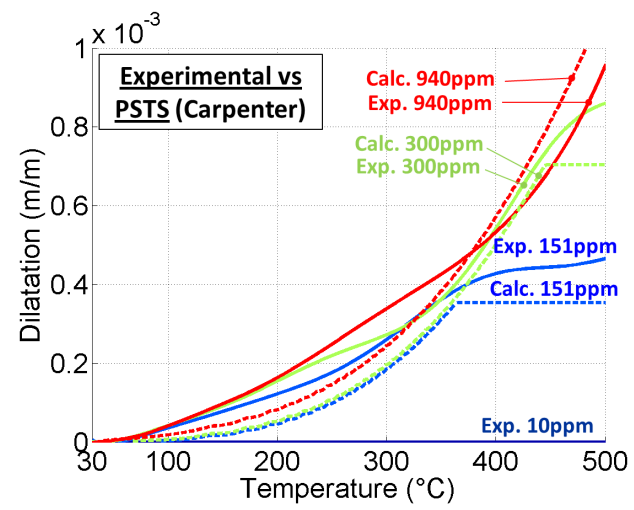

(b)

Figure 8: Experimental (plain lines) and calculated (dotted lines) differential dilatometric curves in $0^{\circ}$ direction for various hydrogen concentration with (a) PLTS and (b) PSTS assumption.

transverse (or circumferential) directions. Only the results for unirradiated cladding are considered here to avoid any possible effects that might arise from the coupling of irradiation and the presence of hydrogen. The measurement at $25{ }^{\circ} \mathrm{C}$ for the unirradiated samples before and after hydriding (and after removing the oxide layer contribution) showed that the dimensional change is isotropic and equal to $\alpha=0.225 \% / 1000 \mathrm{wppm}$. Similar observations of expansion in the axial and transverse directions after hydrogen charging were reported in Seibold et al. [34], Blat-Yrieix [35], Ovejero et al. [36], Krebs et al. [37]. The magnitude of the expansion is limited to $0.1 \%$ for 1000 wppm samples in Blat-Yrieix et al. [35], while it is about $0.2 \%$ in King et al. [33]. One of the likely reasons for this discrepancy between Blat et al. [35] and King et al. [33] is the sample used by Blat et al. have a higher hydrogen concentration beneath the surface than in the bulk of the samples. Therefore, the $0.1 \%$ effective net expansion of Blat et al. [35] may not corresponds to the $1000 \mathrm{wppm}$ average hydrogen content, but likely to the lower hydrogen content in the bulk (without the rim). The isotropic expansion in the axial and circumferential directions observed in King et al. [33] support the PLTS assumption displayed in Figure 6 (a). The agreement is also good in terms of magnitude, which is in the range $2-3 \times 10^{-4 \%} / \mathrm{wppm}$. These results are in contradiction with the anisotropy observed experimentally in the present study, for which the material crystallographic textures were similar. 


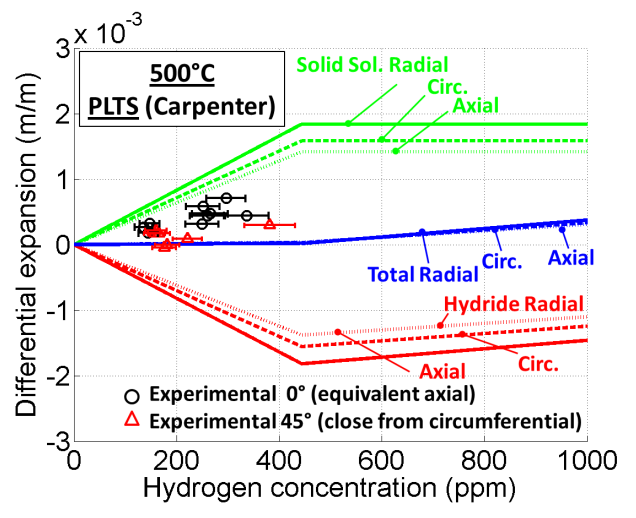

(a)

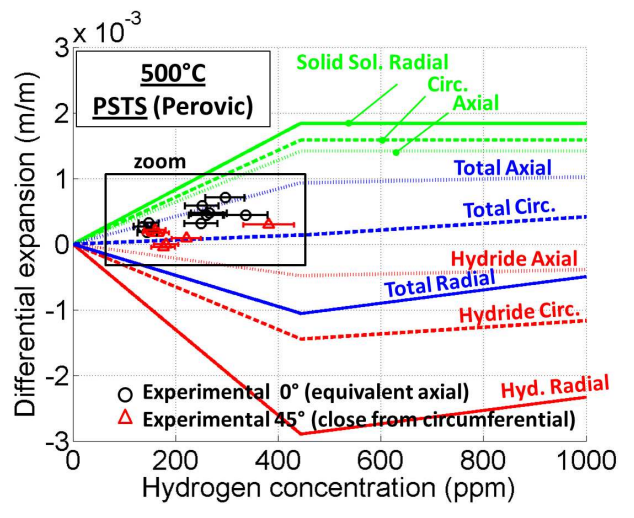

(b)

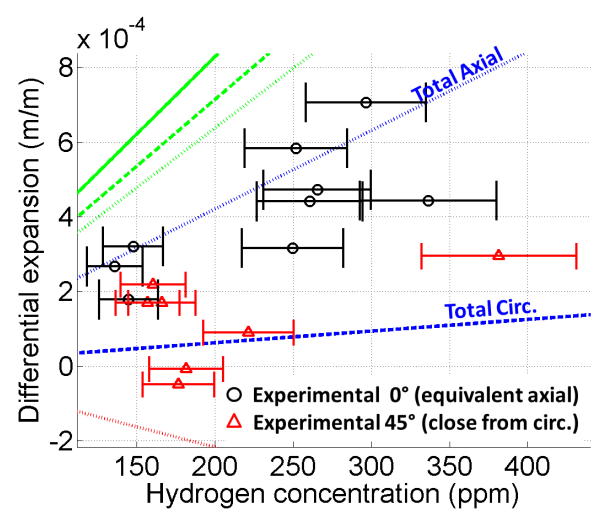

(c)

Figure 9: Contribution of hydrogen in solid solution and hydrides to the expansion of samples heated at $500^{\circ} \mathrm{C}$ with (a) PLTS or (b) PSTS assumption. The Kearns factors are $f_{r}=0.6, f_{\theta}=0.3$ and $f_{z}=0.1$. Figure (c) is a close-up view of Figure (b). 
Part of the explanation may be that the actual hydrides-induced expansion is not purely PSTS, but the present results suggest it is much closer to PSTS than to PLTS. As a consequence, additional experimental confirmation would be valuable to support the conclusions regarding the anisotropy of hydrogen-induced expansion and the validity of using the PSTS assumption. It could include dimensional measurements before and after hydrogen uptake and dilatometric experiments with more pronounced crystallographic texture (measuring $\langle c\rangle$ axis directions would be highly interesting). When using tubes or cladding of standard crystallographic texture, measuring the thickness variation during hydride dissolution could be of interest because the calculation reported in Figure 7 using the PLTS assumption indicated small variations, whereas the PSTS assumption predicted large variations.

In addition, it was shown in Blat-Yrieix et al. [35] that there is less hydride-induced expansion in cold worked stress relieved Zy-4 than in the recrystallized state. A similar result was recently reported by Krebs et al. [37]. Blat-Yrieix et al. [35] suggests it could arise from the higher elasticity limit of the stress relieved material than the recrystallized material. On the other hand, it is known that stress relieved Zy-4 has smaller elongated grains and a high dislocations density compared to recrystallized Zy-4. This could promote strain incompatibilities and reduce the magnitude of the transfer of local hydrogen induced-expansion to a macroscopic scale. The present study is limited to the case where hydrides can be treated as infinitely strong particles in a soft matrix, which is more representative of the recrystallized material than the stress relieved material. More elaborate modeling is required to take into account different material behaviors

\subsection{Numerical application for guide tubes at $350^{\circ} \mathrm{C}$}

Hydrogen-induced expansion can be splitted in two contributions : the hydrogen ingress into the cladding tube and the partition of hydrogen into solid solution and hydrides (plus the differential thermal expansion of hydrides). Axial growth due to hydrogen ingress at $25^{\circ} \mathrm{C}$ is $9.182 \times 10^{-7}$ wppm based on the PSTS assumption and $2.609 \times 10^{-6} /$ wppm based on the PLTS one (Figure 6). A 52MWd/tU Zy-4 guide tube reaches $450 \mathrm{wppm}$ on average over the entire tube length (King et al. [33]). The associated expansion due to hydrogen ingress at $25^{\circ} \mathrm{C}$ is $2.609 \times 10^{-6} / w p p m \times 450 p p m=$ $0.117 \%$ for PLTS and $9.182 \times 10^{-7} / w p p m \times 450 p p m=0.041 \%$ for PSTS On the other hand, the contribution of the partition of hydrogen into hy- 
drides or solid solution at $500{ }^{\circ} \mathrm{C}$ showed in figure 10 was computed again for a $350{ }^{\circ} \mathrm{C}$ temperature (Figure 10). At 450ppm, the total axial expansion (blue dotted line) is equal to $0.013 \%$ for PLTS and $0.032 \%$ for PSTS. Thus, the axial extension of a $3600 \mathrm{~mm}$ tube at $350{ }^{\circ} \mathrm{C}$ and $450 \mathrm{wppm}$ hydrogen would be $0.117 \%+0.013 \%=0.130 \% \times 3600=4.68 \mathrm{~mm}$ for PLTS, and $0.041 \%+0.032 \%=0.073 \% \times 3600=2.63 \mathrm{~mm}$ for PSTS.

One could now compare the hydride contribution to the rod free axial growth during exposure in PWR. It is about $0.6 \%$ at $10^{25} \mathrm{n} / \mathrm{m}^{2} \mathrm{flu}-$ ence on recrystallised Zy-4 cladding tube (Gilbon et al. [38], Doriot et al. [39], Onimus et al. [40]). Thus hydrogen contribution to axial growth is $0.130 \% / 0.6 \%=22 \%$ for PLTS and $0.073 \% / 0.6 \%=12 \%$ for PSTS. Considering the PSTS assumption, the hydrogen-induced expansion is a second order factor in the total cladding free growth.

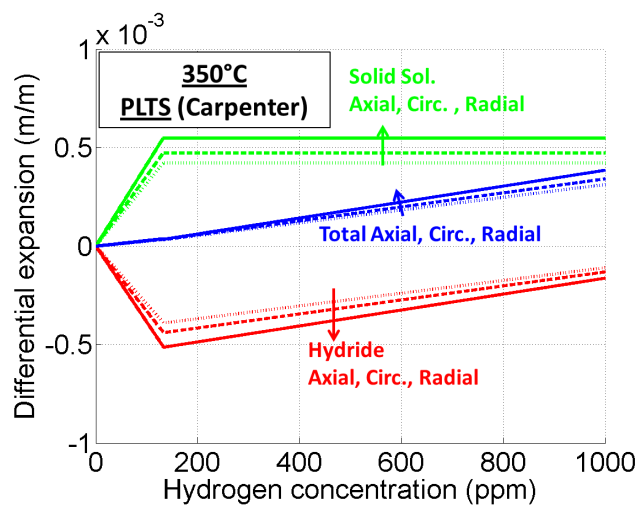

(a)

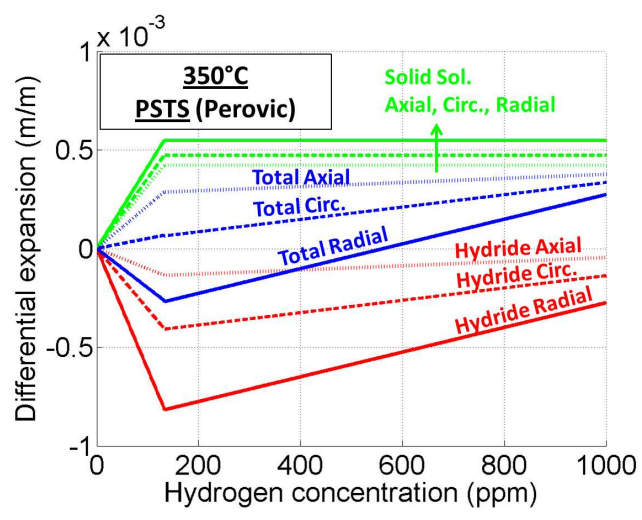

(b)

Figure 10: Contribution of hydrogen in solid solution and hydrides to the expansion of samples heated at $350^{\circ} \mathrm{C}$ with (a) PLTS or (b) PSTS assumption. The Kearns factors are $f_{r}=0.6, f_{\theta}=0.3$ and $f_{z}=0.1$.

\subsection{Radial hydrides impact on dimensional stability}

The present study was focused on hydrides that precipitate on the basal plane or on grain boundaries taking into account the fact that hydrides preferentially precipitate where one of the adjacent grains is favorably oriented (as shown in Qin et al. [41]). The percentage of circumferential and radial hydrides is therefore fixed by the material crystallographic texture. When 
hydrides precipitate under stress, a given fraction could precipitate radially. This would likely have a very limited effect on the axial growth, but would affect the circumferential and thickness dimensions. This point has been studied by Goldthorpe [42], who showed that hydride reorientation induces an increase in diameter. Based on the fraction of reoriented hydrides, the magnitude of the increase was reported to be due to an accommodation of about $11 \% \pm 5 \%$ in the direction normal to the hydride thickness, and $3 \% \pm 2 \%$ in the other two directions. Despite the large uncertainties, these results indicate that hydride accommodation seems closer to the PSTS assumption than the PLTS one.

\section{Conclusion}

The dilatometric experiments on hydrided Zy-4 were satisfactorily simulated taking into account the expansion induced by hydrogen in solid solution and using the "Pure Shear Transformation Strain (PSTS)" assumption proposed by Perovic et al. [29] for precipitated hydrides. This assumption implies that the expansion due to hydride precipitation is completely accommodated in the hydride thickness direction. On the other hand, the dilatometric experiments were not satisfactorily simulated with the "Pure Lattice Transformation Strain (PLTS)" assumption proposed by Carpenter [22], which implies that the expansion due to hydride precipitation is not only accomodated in the hydride thickness direction. The present study results thus indicate that hydride accommodation seems closer to the PSTS assumption than the PLTS one. In addition, it shows it is important to consider the material texture to quantitatively reproduce the material expansion. Under the PSTS assumption, the contribution of hydrides to the axial growth of high-burnup Zy-4 cladding is limited to $12 \%$. However, the PSTS assumption is not supported by the previous experimental results of King et al. [33] and others, who showed that the hydride induced growth at $25^{\circ} \mathrm{C}$ after hydrogen charging is similar in the transverse and longitudinal directions. Additional measurements before and after hydrogen uptake and dilatometric experiments with more pronounced crystallographic textures would be valuable to clarify this point. Eventually, measurements of the zirconium lattice evolution due to the insertion of hydrogen in solid solution would also be valuable because the dilatometric curves obtained suggest that this parameter may increases with temperature. 


\section{Acknowledgements}

The authors wish to thank Sylvain Le Guyot and Laurence Landon for their contribution in performing the dilatometric experiments, Didier Gilbon for useful advices, Thomas Le Jolu and Matthew Bono for careful reviewing. The authors gratefully aknowledge the anonymous reviewer for useful suggestions.

\section{A Data set for $\mathrm{Zr}-\mathrm{H}$ diagram from Thermo- Calc}

\begin{tabular}{|c|c|c|c|c|}
\hline $\begin{array}{c}\text { Temperature } \\
\left({ }^{\circ} \mathrm{C}\right)\end{array}$ & \multicolumn{4}{|c|}{ Hydrogen concentration (wppm) } \\
\hline 521.85 & 543.92 & 15148.84 & 17721.29 & 20583.81 \\
501.85 & 469.63 & 15285.65 & 17730.90 & 20649.08 \\
481.85 & 401.83 & 15414.49 & 17742.95 & 20715.01 \\
461.85 & 340.48 & 15536.00 & 17753.49 & 20764.65 \\
441.85 & 285.48 & 15650.77 & 17769.42 & 20830.73 \\
421.85 & 236.65 & 15759.32 & 17787.40 & 20896.32 \\
401.85 & 193.76 & 15862.11 & 17807.31 & 20960.99 \\
381.85 & 156.53 & 15959.55 & 17829.11 & 21024.34 \\
361.85 & 124.61 & 16052.04 & 17852.75 & 21085.95 \\
341.85 & 97.62 & 16139.89 & 17878.20 & 21145.44 \\
321.85 & 75.14 & 16223.44 & 17905.46 & 21202.42 \\
301.85 & 56.73 & 16302.95 & 17934.57 & 21256.53 \\
281.85 & 41.91 & 16378.69 & 17965.58 & 21307.43 \\
261.85 & 30.23 & 16450.89 & 17998.55 & 21354.83 \\
241.85 & 21.24 & 16519.79 & 18033.58 & 21398.45 \\
221.85 & 14.48 & 16585.58 & 18070.81 & 21438.07 \\
201.85 & 9.54 & 16648.45 & 18110.37 & 21473.52 \\
181.85 & 6.06 & 16708.58 & 18152.44 & 21504.70 \\
161.85 & 3.68 & 16766.14 & 18197.25 & 21531.57 \\
141.85 & 2.13 & 16821.29 & 18245.02 & 21554.19 \\
121.85 & 1.16 & 16874.17 & 18296.03 & 21572.72 \\
101.85 & 0.59 & 16924.91 & 18350.60 & 21587.39 \\
81.85 & 0.28 & 16973.65 & 18409.07 & 21598.55 \\
61.85 & 0.12 & 17020.50 & 18471.86 & 21606.64 \\
41.85 & 0.05 & 17065.57 & 18539.40 & 21612.17 \\
21.85 & 0.02 & 17108.98 & 18612.20 & 21615.69 \\
\hline & & & & \\
& & & & \\
& & & &
\end{tabular}

Table 2: Thermo-Calc output results for the $\mathrm{Zr}-\mathrm{H}$ phase diagram 


\section{References}

[1] P. Barberis, V. Rebeyrolle, J. Vermoyal, V. Chabretou, J. Vassault, CASTA DIVA : Experiments and modeling of oxide-induced deformation in nuclear components, Limback, M. and Kammenzind, B. F. (Eds), ASTM STP 1505, Sunriver, Oregon, 2007, pp. 612-630.

[2] J. Bradbrook, G. Lorimer, N. Ridley, The precipitation of zirconium hydride in zirconium and Zircaloy-2, Journal of Nuclear Materials 42 (1972) pp. 142-160.

[3] J. Root, W. Small, D. Khatamian, O. Woo, Kinetics of the gamma to delta zirconium hydride transformation in $\mathrm{Zr}-2.5 \mathrm{Nb}$, Acta Materialia 51 (7) (2003) pp. 2041-2053.

[4] A. Barrow, A. Korinek, M. Daymond, Evaluating zirconium-zirconium hydride interfacial strains by nano-beam electron diffraction, Journal of Nuclear Materials 432 (2013) pp. 366-370.

[5] C. Ells, Hydride precipitates in zirconium alloys (a review), Journal of Nuclear Materials 28 (1968) pp. 129-151.

[6] E. Zuzek, J. Abriata, The H-Zr system, Bulletin of alloy-phase diagrams 11 (4) (1990) pp. 385-395.

[7] L. Thuinet, R. Besson, Ab initio, study of competitive hydride formation in zirconium alloys, Intermetallics 20 (1) (2012) pp. 24-32.

[8] J. Brachet, L. Portier, T. Forgeron, J. Hivroz, D. Hamon, T. Guilbert, T. Bredel, P. Yvon, J.-P. Mardon, P. Jacques, Influence of hydrogen content on the alpha/beta phase transformation temperatures and on the thermal-mechanical behavior of Zy-4, M4 and M5 alloys during the first phase of LOCA transient, Moan, G.D. and Rudling, P. (Eds), ASTM STP 1423, West Conshohocken, PA, 2001, pp. 673-701.

[9] K. Murty, I. Charit, Texture development and anisotropic deformation of Zircaloys, Progress in Nuclear Energy 48 (2006) pp. 325-359.

[10] B. Kammenzind, D. Franklin, W. Duffin, H. Peters, Hydrogen pickup and redistribution in alpha-annealed Zircaloy-4, Bradley, E.R. and 
Sabol, G.P. (Eds), ASTM STP 1295, Garmisch-Partenkirchen, Germany, 1996, pp. 338-370.

[11] J. Kearns, Terminal solubility and partitioning of hydrogen in the alpha phase of zirconium, Zircaloy-2 and Zircaloy-4, Journal of Nuclear Materials 22 (3) (1967) pp. 292-303.

[12] R. Tang, X. Yang, Dissolution and precipitation behaviors of hydrides in N18, Zry-4 and M5 alloys, International Journal of Hydrogen Energy 34 (17) (2009) pp. 7269-7274.

[13] A. Sawatzky, The diffusion and solubility of hydrogen in the alpha phase of Zircaloy-2, Journal of Nuclear Materials 2 (1960) pp. 62-68.

[14] W. Erickson, D. Hardie, The influence of alloying elements on the terminal solubility of hydrogen in alpha-zirconium, Journal of Nuclear Materials 13 (1964) pp. 254-262.

[15] K. Une, S. Ishimoto, Dissolution and precipitation behavior of hydrides in Zircaloy-2 and high Fe Zircaloy, Journal of Nuclear Materials 322 (1) (2003) pp. 66-72.

[16] K. Une, S. Ishimoto, Terminal solid solubility of hydrogen in unalloyed zirconium by differential scanning calorimetry, Journal of Nuclear Science and Technology 41 (9) (2004) pp. 949-952.

[17] R. Singh, S. Mukherjee, A. Gupta, S. Banerjee, Terminal solid solubility of hydrogen in Zr-alloy pressure tube materials, Journal of Alloys and Compounds 389 (1-2) (2005) pp. 102-112.

[18] N. Dupin, I. Ansara, C. Servant, C. Toffolon, C. Lemaignan, J. Brachet, A thermodynamic database for zirconium alloys, Journal of Nuclear Materials 275 (1999) pp. 287-295.

[19] S. R. Mac Ewen, C. E. Coleman, C. E. Ells, J. Faber Jr, Dilation of hcp zirconium by interstitial deuterium, Acta Metallurgica 33 (5) (1985) pp. 753-757.

[20] R. Eadie, K. Tashiro, D. Harrington, M. Leger, The determination of the partial molar volume of hydrogen in zirconium in a simple stress gradient using comparative microcalorimetry, Scripta Metallurgica et Materialia 26 (2) (1992) pp. 231-236. 
[21] O. Zanellato, M. Preuss, J. Buffiere, F. Ribeiro, A. Steuwer, J. Desquines, J. Andrieux, B. Krebs, Synchrotron diffraction study of dissolution and precipitation kinetics of hydrides in Zircaloy-4, Journal of Nuclear Materials 420 (2011) pp. 537-547.

[22] G. Carpenter, The dilatation misfit of zirconium hydrides precipitated in zirconium, Journal of Nuclear Materials 48 (1973) pp. 264-266.

[23] R. Singh, P. Stahle, A. Massih, A. Shmakov, Temperature dependence of misfit strains of delta-hydrides of zirconium, Journal of Alloys and Compounds 436 (2007) pp. 150-154.

[24] R. Versaci, M. Ipohorski, Temperature dependance of lattice parameters of alpha-zirconium, Tech. rep., CNEA-500 (1991).

[25] J. Goldak, L. T. Lloyd, C. S. Barrett, Lattice Parameters, Thermal Expansions, and Gruneisen Coefficients of Zirconium, 4.2 to 1130K, Physical Review 144 (2) (1966) pp. 478-484.

[26] IAEA, Thermophysical properties of materials for nuclear engineering: a tutorial and collection of data, IAEA, 2008.

[27] S. Yamanaka, K. Yamada, K. Kurosaki, M. Uno, K. Takeda, H. Anada, T. Matsuda, S. Kobayashi, Thermal properties of zirconium hydride, Journal of Nuclear Materials 294 (1-2) (2001) pp. 94-98.

[28] G. Weatherly, The precipitation of gamma-hydride plates in zirconium, Acta Metallurgica 29 (3) (1981) pp. 501-512.

[29] V. Perovic, G. Weatherly, L. Simpson, Hydride precipitation in alpha/beta zirconium alloys, Acta Metallurgica 31 (9) (1983) pp. 13811391 .

[30] Z. Pan, I. Ritchie, M. Puls, The terminal solid solubility of hydrogen and deuterium in Zr-2.5Nb alloys, Journal of Nuclear Materials 228 (2) (1996) pp. 227-237.

[31] A. McMinn, E. Darby, J. Schofield, The terminal solid solubility of hydrogen in zirconium alloys, Sabol, G.S. and Moan, G.D. (Eds), ASTM STP 1354, Toronto, Canada, 2000, pp. 173-195. 
[32] E. Tulk, M. Kerr, M. Daymond, Study on the effects of matrix yield strength on hydride phase stability in Zircaloy-2 and Zr 2.5Nb, Journal of Nuclear Materials 425 (2012) pp. 93-104.

[33] S. King, R. Kesterson, K. Yueh, R. Comstock, H. W.M., F. S.D., Impact of hydrogen on dimensional stability of Zirlo fuel assemblies, in: R. Herwig, W. Ferguson (Eds.), 13th International Symposium on Zirconium in the Nuclear Industry, ASTM STP 1423, West Conshohocken, PA, 2002, pp. 471-489.

[34] A. Seibold, F. Garzarolli, R. Manzel, Material development for siemens fuel elements, International Topical Meeting on Light Water Reactor Fuel Performance, American Nuclear Society, Park City, Utah, 2000.

[35] M. Blat-Yrieix, A. Amnard, F. Foct, A. Miquet, S. Beguin, N. Cayet, Toward a better understanding of dimensional changes in Zircaloy-4 : What is the impact induced by hydrides and oxide layer?, Limback, M. and Kammenzind, B. F. (Eds), ASTM STP 1505, Sunriver, Oregon, 2007.

[36] J. Ovejero, A. Banchik, P. Vizcaino, Axial / Tangential expansion coefficients of Zircaloy-4 channels due to the hydrogen pick up, Advances in Technology of Materials and Materials Processing Journal 10 (2008) pp. $1-8$.

[37] B. Krebs, J. Desquines, D. Drouan, S. Guilbert, C. Duriez, P. March, Characterization and modeling of the combined influence of hydrogen and oxydation on fuel cladding dimensional stability, International Topical Meeting on Light Water Reactor Fuel Performance / Design and Materials, European Nuclear Society, Manchester, United Kingdom, 2012, pp. 369-378.

[38] D. Gilbon, A. Soniak, S. Doriot, J. Mardon, Irradiation creep and growth behavior, and microstructural evolution of advanced zr-base alloys, Sabol, G.P. and Moan, G.D. (Eds), ASTM STP 1354, Toronto, Canada, 2000, pp. 51-73.

[39] S. Doriot, D. Gilbon, J. Bchade, M. Mathon, L. Legras, J. Mardon, Microstructural stability of M5 alloy irradiated up to high neutron fluences, 
Kammenzind, B. and Rudling, P. (Eds), ASTM STP 1467, Stockholm, Sweden, 2005, pp. 175-201.

[40] F. Onimus, J. Bchade, Radiation effects in zirconium alloys (section 4.01), Comprehensive Nuclear Materials 4 (2012) pp. 1-31.

[41] W. Qin, N. Kiran Kumar, J. Szpunar, J. Kozinski, Intergranular delta hydride nucleation and orientation in zirconium alloys, Acta Materialia 59 (18) (2011) pp. 7010-7021.

[42] S. Goldthorpe, Analysis of hydride effects in Zr-2.5Nb micro-pressure tube, Master of science, Queens University, Kingston, Ontario, Canada (2010). 